\title{
$\mathrm{BCTZ}$ 첨가가 NKLN-AS계 압전세라믹스의 미세구조와 압전/유전특성 및 상전이현상에 미치는 효과 \\ 이웅재**** 어순철**** 이영근* - 윤만순**† \\ *충주대학교 신소재공학과, **친환경 에너지 부품소재센터
}

\section{BCTZ Addition on the Microstructure, Piezoelectric/Dielectric Properties and Phase Transition of NKLN-AS Piezoelectric Ceramics}

\author{
Woong Jae Lee***, Soon Chul Ur***, Young Geun Lee* and Man Soon Yoon**† \\ *Department of Materials Science and Engineering, Chungju National University \\ **Research Center for Sustainable Eco-Devices and Materials (ReSEM)
}

(2011년 11월 16일 접수 : 2011년 11월 30일 최종수정 : 2011년 12월 1일 채택)

\begin{abstract}
Presently, the most promising family of lead-free piezoelectric ceramics is based on $\mathrm{K}_{0.5} \mathrm{Na}_{0.5} \mathrm{NbO}_{3}(\mathrm{KNN})$. Lithium, silver and antimony co-doped KNN ceramics show high piezoelectric properties at room temperature, but often suffer from abnormal grain growth. In the present work, the $\left(\mathrm{Ba}_{0.85} \mathrm{Ca}_{0.15}\right)\left(\mathrm{Ti}_{0.88} \mathrm{Zr}_{0.12}\right) \mathrm{O}_{3}$ component, which has relaxor ferroelectric characteristics, was doped to suppress the abnormal grain growth. To investigate this effect, Lead-Free $0.95\left(\mathrm{~K}_{0.5} \mathrm{Na}_{0.5}\right)_{0.95} \mathrm{Li}_{0.05}$ $\mathrm{NbO}_{3}-(0.05-\mathrm{x}) \mathrm{AgSbO}_{3}-\mathrm{x}\left(\mathrm{Ba}_{0.85} \mathrm{Ca}_{0.15}\right)\left(\mathrm{Ti}_{0.88} \mathrm{Zr}_{0.12}\right) \mathrm{O}_{3}[\mathrm{KNLN}-\mathrm{AS}-\mathrm{xBCTZ}]$ piezoelectric ceramics were synthesized by ball mill and nanosized-milling processes in lead-Free $0.95\left(\mathrm{~K}_{0.5} \mathrm{Na}_{0.5}\right)_{0.95} \mathrm{Li}_{0.05} \mathrm{NbO}_{3}-(0.05-\mathrm{x}) \mathrm{AgSbO}_{3}$ in order to suppress the abnormal grain growth. The nanosized milling process of calcined powders enhanced the sintering density. The phase structure, microstructure, and ferroelectric and piezoelectric properties of the KNLN-AS ceramics were systematically investigated. XRD patterns for the doped and undoped samples showed perovskite phase while tetragonality was increased with increasing BCZT content, which increase was closely related to the decrease of TO-T. Dense and uniform microstructures were observed for all of the doped BCZT ceramics. After the addition of BCTZ, the tetragonal-cubic and orthorhombic-tetragonal phase transitions shifted to lower temperatures compared to those for the pure KNNL-AS. A coexistence of the orthorhombic and tetragonal phases was hence formed in the ceramics with $\mathrm{x}=0.02 \mathrm{~mol}$ at room temperature, leading to a significant enhancement of the piezoelectric properties. For the composition with $\mathrm{x}=0.02 \mathrm{~mol}$, the piezoelectric properties showed optimum values of: $\mathrm{d}_{33}=185 \mathrm{pC} / \mathrm{N}, \mathrm{k}_{\mathrm{P}}=41 \%, \mathrm{~T}_{\mathrm{C}}=325^{\circ} \mathrm{C}, \mathrm{T}_{\mathrm{O}-\mathrm{T}}=-4^{\circ} \mathrm{C}$.
\end{abstract}

Key words $\mathrm{KNN}$, piezoelectric properties, dielectric properties, phase transition.

\section{1. 서 론}

$\mathrm{Pb}(\mathrm{Zr}, \mathrm{Ti}) \mathrm{O}_{3}, \mathrm{~Pb}\left(\mathrm{Mg}_{1 / 3} \mathrm{Nb}_{2 / 3}\right) \mathrm{O}_{3}-\mathrm{PbTiO}_{3}, \mathrm{~Pb}\left(\mathrm{Zn}_{1 / 3} \mathrm{Nb}_{2 / 3}\right)-$ $\mathrm{PbTiO}_{3}$ 와 같이 페로브스카이트 구조를 갖는 납(Lead)계 압전세라믹스는 우수한 압전/유전특성을 갖고 있으며, 액 튜에이터, 센서 등에 널리 사용되고 있다. ${ }^{1-2)}$ 그러나 이 러한 PZT등의 납 (lead)계 소재는 다량의 $\mathrm{Pb}$ 를 함유하고 있어서 환경오염과 인체에 유해하여 최근 선진국을 중심 으로 WEEE (Waste Electrical and Electronic Equipment) 와 RoHS (Restriction of Hazardous Substances)등에 의해 제한되고 있으며, 그에 따라 환경친화적인 재료의 개발

${ }^{\dagger}$ Corresponding author

E-Mail : msyoon@cjnu.ac.kr (M. -S.Yoon)
에 대하여 관심이 고조되고 있다.-4)

현재 활발히 연구 중인 lead-free 압전 소재로는 tungsten bronze계, Bi-layer계, $(\mathrm{Bi}, \mathrm{Na}) \mathrm{TiO}_{3}(\mathrm{BNT})$ 계, $(\mathrm{K}, \mathrm{Na})$ $\mathrm{NbO}_{3}(\mathrm{KNN})$ 계, $\mathrm{BaTiO}_{3}(\mathrm{BT})$ 계 등의 5 가지 정도로 구 분할 수 있다. 이들 비납계 재료 중에서 $\mathrm{KNN}$ 계의 소 재가 높은 큐리온도 $\left(420^{\circ} \mathrm{C}\right)$ 와 우수한 전기기계결합계수를 갖고 있어 유망한 재료로 주목 받고 있다. ${ }^{5)} \mathrm{KNN}$ 계 소 재는 $\mathrm{K}_{\mathrm{p}}=0.34 \sim 0.39, \mathrm{~T}_{\mathrm{c}}=415^{\circ} \mathrm{C}, \mathrm{d}_{33}=120 \mathrm{pC} / \mathrm{N}$ 로 비교 적 우수한 특성을 나타내고 있으나, 소결과정에서 $\mathrm{K}_{2} \mathrm{O}$ 와 $\mathrm{NaO}$ 의 높은 휘발성 때문에 통상적인 소결방법에 의 하여 치밀한 소결체를 제조하기 어려워 우수한 물성을 얻기 어려운 문제점을 나타내고 있다. ${ }^{6}$ 따라서, 최근의 연구자들은 이러한 문제점을 해소하기 위하여 $\mathrm{KNN}$ 재료 에 다른 강유전체 물질을 고용시키거나 소결 조제를 이 
용하여 이 문제점을 해결하려는 연구를 진행하고 있다. 예를 들면 $\mathrm{KNN}-\mathrm{Bi}_{0.5} \mathrm{Na}_{0.5} \mathrm{Ti}_{\mathrm{O}}{ }^{7}{ }^{7}{ }^{7} \mathrm{KNN}-\mathrm{LiNbO}_{3}{ }^{8}, \mathrm{KNN}-$ $\mathrm{BaTiO}_{3},{ }^{9)} \mathrm{KNN}-\mathrm{LiSbO}_{3},{ }^{10)} \mathrm{KNN}-\mathrm{BiAlO}_{3},{ }^{11)} \mathrm{KNN}-\mathrm{Li}(\mathrm{Nb}$, $\mathrm{Ta}, \mathrm{Sb}) \mathrm{O}_{3}{ }^{12)} \mathrm{KNN}^{12} \mathrm{BiScO}_{3}{ }^{13)}$ 와 같은 고용체를 연구하거 나, $\mathrm{K}_{5.4} \mathrm{Cu}_{1.3} \mathrm{Ta}_{10} \mathrm{O}_{29}{ }^{14)}$ 와 같은 소결 조제를 이용한 연구 가 수행되었다.

PZT계 압전세라믹스에 연구된 결과에 따르면, 다성분 계 압전재료는 단성분계나 이성분계 압전재료에 비하여 우 수한 특성을 나타내는 것으로 알려져 있다. ${ }^{15)}$ 따라서, 본 연구 에서는 선행 연구된 $\left(\mathrm{K}_{0.5} \mathrm{Na}_{0.5}\right)_{0.95} \mathrm{Li}_{0.05} \mathrm{NbO}_{3}-\mathrm{AgSbO}_{3}$ 이성분계 재료 ${ }^{16)}$ 에 전형적인 완화형 강유전체 특성을 갖 는 것으로 알려진 $\left(\mathrm{Ba}_{0.85} \mathrm{Ca}_{0.15}\right)\left(\mathrm{Ti}_{0.88} \mathrm{Zr}_{0.12}\right)^{17)}$ 를 첨가하여 $0.95\left(\mathrm{~K}_{0.5} \mathrm{Na}_{0.5}\right)_{0.95} \mathrm{Li}_{0.05} \mathrm{NbO}_{3}-(0.05-\mathrm{x}) \mathrm{AgSbO}_{3}-\mathrm{xBCTZ}$ [KNLN-AS -xBCTZ] 3성분계 재료를 통상적인 볼밀공 정에 의하여 제조한 후 하소 후 소결성을 증진시키기 위 하여 고에너지밀에 의하여 나노분쇄 후 $\mathrm{BCTZ}$ 의 첨가량 이 1) 상전이 온도와 2) 압전/유전특성에 미치는 효과를 관찰하였으며, 마지막으로 3) 미세구조에 미치는 영향을 조사하였다.

\section{2. 실험 방법}

본 연구에서는 페로브스카이트 구조를 갖는 $0.95\left(\mathrm{~K}_{0.5^{-}}\right.$ $\left.\mathrm{Na}_{0.5}\right)_{0.95} \mathrm{Li}_{0.05} \mathrm{NbO}_{3}$-(0.05-x) $\mathrm{AgSbO}_{3}-\mathrm{x}\left(\mathrm{Ba}_{0.85} \mathrm{Ca}_{0.15}\right) \mathrm{Ti}_{0.88} \mathrm{Zr}_{0.12}$ $\mathrm{O}_{3}$ [KNLN-AS-xBCTZ] $(\mathrm{x}=0,0.02,0.04,0.05 \mathrm{~mol})$ 세라 믹스를 제조하기 위하여 $\left(\mathrm{K}_{0.5} \mathrm{Na}_{0.5}\right)_{0.95} \mathrm{Li}_{0.05} \mathrm{NbO}_{3}[\mathrm{KNLN}]$ 과 $\mathrm{AgSbO}_{3}[\mathrm{AS}]$ 와 $\left(\mathrm{Ba}_{0.85} \mathrm{Ca}_{0.15}\right)\left(\mathrm{Ti}_{0.88} \mathrm{Zr}_{0.12}\right)$ [BCTZ] 를 각 각 합성하였다. 모상인 $\mathrm{KNLN}$ 을 합성하기 위하여 출발 원 료로 $\mathrm{Na}_{2} \mathrm{CO}_{3}, \mathrm{~K}_{2} \mathrm{CO}_{3}, \mathrm{Nb}_{2} \mathrm{O}_{5}, \mathrm{Li}_{2} \mathrm{CO}_{3}$ 를 사용하여 화학양 론적으로 평량한 후 에틸알콜(ethyl alcohol)을 분산매로 하여 반응성을 높이기 위하여 고에너지밀을 이용하여 30 분간 혼합 및 분쇄과정을 수행하였으며, 소량 첨가되는 첨 가제 가운데, $\mathrm{AgSbO}_{3}$ 를 제조하기 위하여 $\mathrm{Ag}_{2} \mathrm{O}, \mathrm{Sb}_{2} \mathrm{O}_{5}$ 을 화학양론적으로 평량하여 에틸알콜(ethyle alcohol)을 분산 매로 지르코니아 볼을 사용하여 24시간 동안 볼밀을 사 용하여 혼합 분쇄하였다. 또 다른 첨가제인 $\mathrm{BCTZ}$ 를 제 조하기 위하여 $\mathrm{BaCO}_{3}, \mathrm{CaCO}_{3}, \mathrm{TiO}_{2}, \mathrm{ZrO}_{2}$ 를 화학양론적 으로 평량한 후 $\mathrm{AgSbO}_{3}$ 제조와 동일한 방법으로 혼합 분 쇄 하였다.

각각의 혼합된 원료를 $100^{\circ} \mathrm{C}$ 의 전기오븐에서 12 시간 건 조 후 분당 $5^{\circ} \mathrm{C}$ 의 승온속도로 각각 $650^{\circ} \mathrm{C}, 850^{\circ} \mathrm{C}, 950^{\circ} \mathrm{C}$ 에서 4 시간 동안 하소하였다. 하소된 분말들을 설계된 조 성에 맞도록 평량한 후 나노크기의 분말을 제조하기 위하 여 나노 분쇄기(NETZECH LABSTAR)를 이용하여 에탄 올을 분산매로하여 $0.1 \mathrm{~mm}$ 와 $0.3 \mathrm{~mm}$ 의 혼합 비즈(beads) 를 이용하여 $3000 \mathrm{rpm}$ 으로 30 분 동안 분쇄 하였다.
분쇄된 분말들은 $100^{\circ} \mathrm{C}$ 의 전기오븐에서 12 시간 건조 하고 채가름 후 디스크형 금형 $(\Phi 15 \mathrm{~mm})$ 를 이용하여 가 성형 후 $\mathrm{CIP}$ 를 이용 $147.1 \mathrm{MPa}$ 의 압력으로 성형체를 제 조하였다. 성형한 시료는 $1000^{\circ} \mathrm{C}$ 에서 $1160^{\circ} \mathrm{C}$ 까지 온도 대역에서 분당 $3^{\circ} \mathrm{C}$ 의 승온 속도로 4 시간 동안 소결하였 다. 소결된 시료의 결정상을 확인하기 위하여 $\mathrm{X}$ 선 회절 분석(XRD; Rigaku D/MAX-2500H)을 하였으며, 미세구 조의 관찰을 위해서 주사전자현미경(SEM, FEI Company Quanta400)을 사용하였다.

전극 형성을 위해 소결 시편의 양쪽 면을 양면연마기 를 이용하여 연마한 후, 전도성 은 전극(silver paste)을 도 포하여 $560^{\circ} \mathrm{C}$ 에서 30 분간 소부하였다. 압전성을 부여하기 위한 분극공정은 $150^{\circ} \mathrm{C}$ 로 유지한 실리콘 오일 항온조에 서 시편에 각 시편당 $10 \mathrm{kV} / \mathrm{mm}$ 의 전계를 가하여 40 분 간 분극처리 하였다.

분극 처리된 시편을 $150^{\circ} \mathrm{C}$ 에서 5 시간 시효 한 후Impedance/Gain phase Analyzer(HP model: 4194A)를 사용하 여 압전 세라믹스 특성측정에 관한 IRE 표준공진-반공 진 방법에 따라 압전 특성을 측정 하였으며 $\mathrm{d}_{33}$ meter (IACAS: model ZJ-6B)를 이용하여 압전상수 $\left(\mathrm{d}_{33}\right)$ 를 측정 하였다. 온도변화에 따른 유전율 및 유전손실의 온도의존 성을 측정하기 위하여 $-30 \sim 450^{\circ} \mathrm{C}$ 온도구간에서 자체 제 작된 자동측정장치를 이용하였다. 온도는 저온구역 $(-30$ $200^{\circ} \mathrm{C}$ )은 액체질소를 사용하는 저온 로(Delta Design Inc: model Delta 9023)를 이용하였으며 $200^{\circ} \mathrm{C}$ 이상의 온도구 간에서는 관 형로(Lindberg Tube Furnace: model Blue $\mathrm{M}$ )를 이용하였다. 온도 제어는 로의 온도 제어부를 데스 크탑 컴퓨터와 연결하여 자동으로 조절하였으며, 시편의 온도변화는 시편 옆에 장착된 K-typ열전대와 Keithley 740 thermometer을 이용하여 측정하였다. P-E 이력곡선은 Precision LC system (Radiant Technology: Model 610E) 을 사용하였다.

\section{3. 결과 및 고찰}

하소 된 원료를 고 에너지 밀을 사용하여 나노 크기 로 분쇄하였으며, 그 결과를 Fig. 1에서 보여주고 있다. 입자크기는 모든 시료에서 $180 \sim 200 \mathrm{~nm}$ 의 크기를 나타내 고 있다. 이와 같이 혼합 분쇄된 나노 원료를 $1050^{\circ} \mathrm{C}$ 에 서 소결한 후 $\mathrm{X}$ 선 회절 분석에 의하여 결정상을 상온 에서 확인하였다.

Fig. 2(a) (d)는 $1050^{\circ} \mathrm{C}$ 에서 소결한 시편의 $\mathrm{BCZT}$ 첨가 량에 따른 X-선회절 패턴을 나타내고 있다. 모든 시료에 서 순수 페로브스카이트 결정구조를 나타내고 있으며, 2 차상은 관찰되지 않았으며, 또한 회절강도의 위치와 모 양은 크게 변하지 않았다. 즉, 첨가된 $\mathrm{AS}$ 와 $\mathrm{BCTZ}$ 는 균 

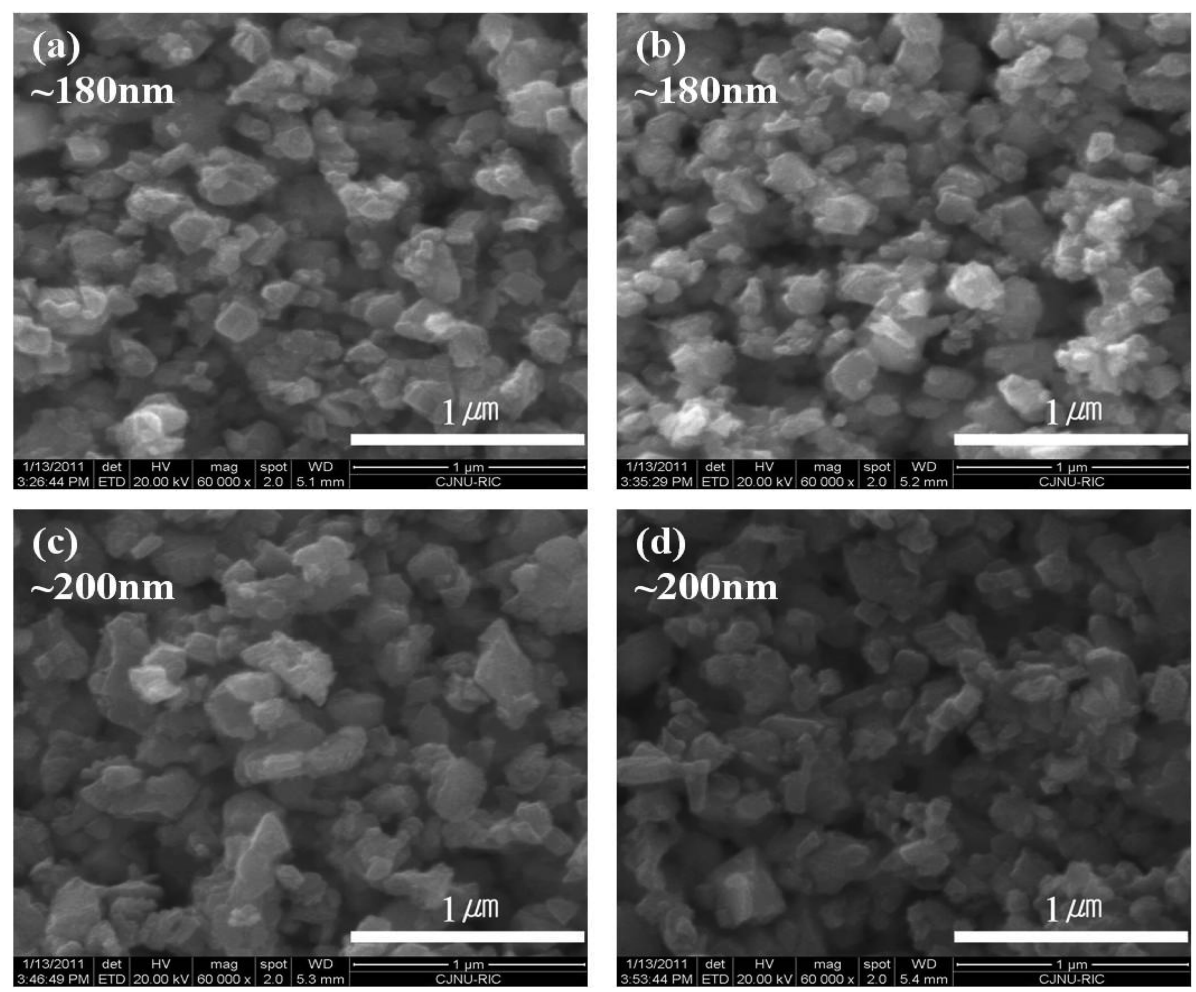

Fig. 1. The SEM morphology of nano milled KNLN-AS-xBCTZ powders: (a) $x=0$ mol, (b) $x=0.02 \mathrm{~mol}$, (c) $x=0.04 \mathrm{~mol}$ and (d) $x=$ $0.05 \mathrm{~mol}$

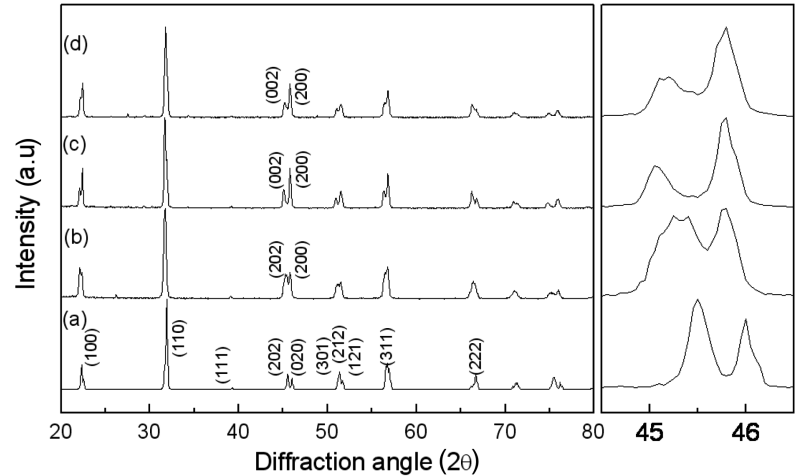

Fig. 2. XRD patterns of sintered KNLN-AS-xBCZT samples: (a) $\mathrm{x}=0 \mathrm{~mol}$, (b) $\mathrm{x}=0.02 \mathrm{~mol}$, (c) $\mathrm{x}=0.04 \mathrm{~mol}$ and (d) $\mathrm{x}=0.05 \mathrm{~mol}$.

질한 페로브스카이트상을 형성하기 위하여 $\mathrm{KNN}$ 격자로 확 산 고용되었다는 사실을 나타낸다. $2 \theta=45^{\circ}$ 부근의 회절 피크를 분석한 결과, Fig. 2(a)의 BCTZ가 첨가되지 않 은 KNLN-AS 세라믹스는 $(202) /(020)$ 피크를 나타내며 이 는 사방정계 결정구조를 나타내고 있어, $\mathrm{BCTZ}$ 의 첨가 량이 증가할수록 정방정계의 결정구조로 변화하는 것을 알 수 있다. 즉, $\mathrm{BCTZ}$ 가 $0.04 \mathrm{~mol}$ 이상 첨가 시 정방정 상만이 존재하는 것을 알 수 있다. BCTZ의 첨가량증가 에 따른 결정구조의 변화는 $\mathrm{KNN}$ 계의 사방정계-정방정계 상전이 온도와 연관되어 있으므로, Fig. 3 에 $1 \mathrm{kHz}$ 에서
의 각 조성에 대한 유전율의 온도의존성을 측정한 결과 를 나타내었다.

Fig. 3(a)는 $\mathrm{x}=0,0.02,0.04,0.05 \mathrm{~mol}$ 이 첨가된 $\mathrm{KNN}-$ $\mathrm{AS}-\mathrm{xBCTZ}$ 세라믹스의 온도변화에 따른 유전율의 의존 성을 보여주며, Fig. 3(b)는 각 조성에 대한 상전이온도 의 변화를 정리한 결과이다. KNLN-AS- $0.00 \mathrm{BCTZ} \mathrm{mol}$ 의 조성의 경우(즉, $\mathrm{BCZT}$ 가 첨가되지 않은 경우) 정방정입방정의 상전이 온도 $\left(\mathrm{T}_{\mathrm{c}}\right) 340^{\circ} \mathrm{C}$ 를 나타내고 있으며, 사 방정-정방정 상전이온도 $\left(\mathrm{T}_{\mathrm{O}-\mathrm{T}}\right)$ 는 $65^{\circ} \mathrm{C}$ 를 나타내고 있다 (Fig. 3에 삽입된 그림 참조). 또한, 각각의 상전이 온도 곡선은 비교적 급격한 유전율의 변화를 나타내고 있다. $\mathrm{BCTZ}$ 를 첨가한 경우 온도 유전율 곡선은 유사한 온도의 존성을 나타내고 있으나, 두 개의 상전이 온도 $\left(\mathrm{T}_{\mathfrak{c}}, \mathrm{T}_{\mathrm{O}-\mathrm{T}}\right)$ 는 낮은 온도로 이동하는 것을 알 수 있다.

$\mathrm{BCTZ}$ 첨가량이 증가함에 따라 Fig. 3(a)에 나타난 바 와 같이 완화형 강유전체의 전형적인 현상인 확산형상전 이 현상이 두 개의 상전이 온도에서 동시에 나타나는 것 을 알 수 있다. 이러한 현상은 BCTZ첨가에 의하여 $\mathrm{KNN}$ 의 $\mathrm{A}, \mathrm{B}$ 자리의 치환이 발생하고, 따라서 각각의 자리에 불규칙성이 증가하는 현상과 연관 지어질 수 있으며, 이 와 유사한 현상이 $\mathrm{KNN}-\mathrm{CaTiO}_{3}{ }^{18)} \mathrm{KNN}^{1}-\mathrm{BaTiO}_{3}{ }^{19)}$ 세라 믹스에서도 관찰되고 있다. Fig. 3(b)로 부터, $\mathrm{x}$ 값이 0.00 $\mathrm{mol}$ 에서 $0.02 \mathrm{~mol}$ 로 증가함에 따라 $\mathrm{T}_{\mathrm{c}}$ 는 $340^{\circ} \mathrm{C}$ 에서 $325^{\circ} \mathrm{C}$ 

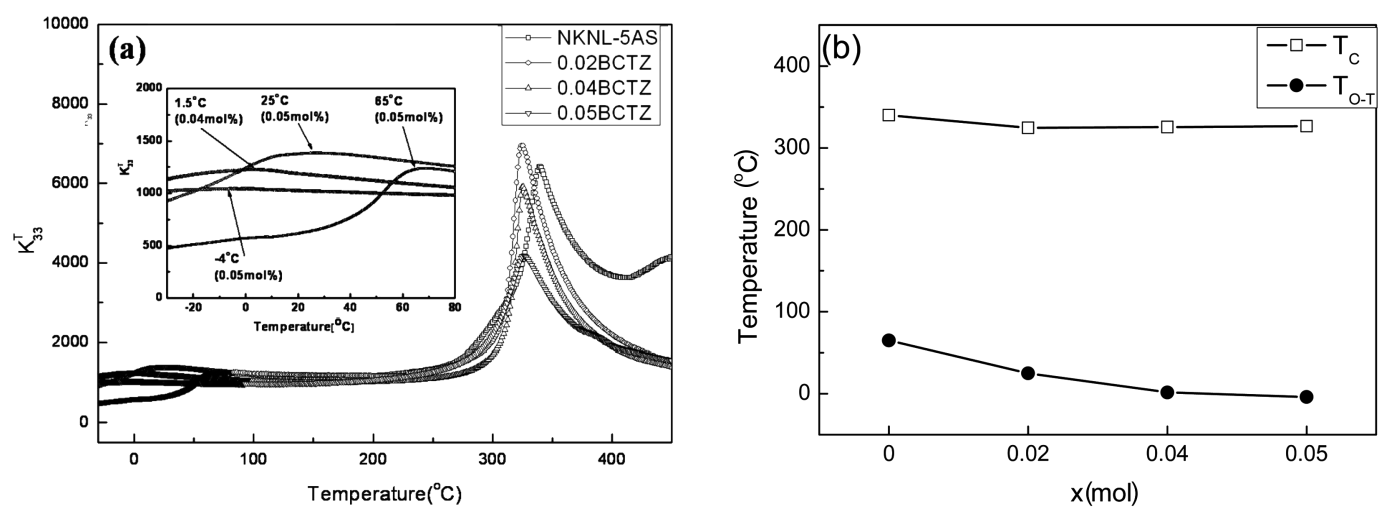

Fig. 3. (a) Relative dielectric permittivity $\left(\mathrm{K}^{33} \mathrm{~T}\right)$ as a function of temperature for the KNLN-AS-xBCTZ ceramics (measured at $\left.1 \mathrm{kHz}\right)$ and (b) variation of phase transition temperatures with $\mathrm{x}$ for the KNLN-AS-xBCTZ ceramics.
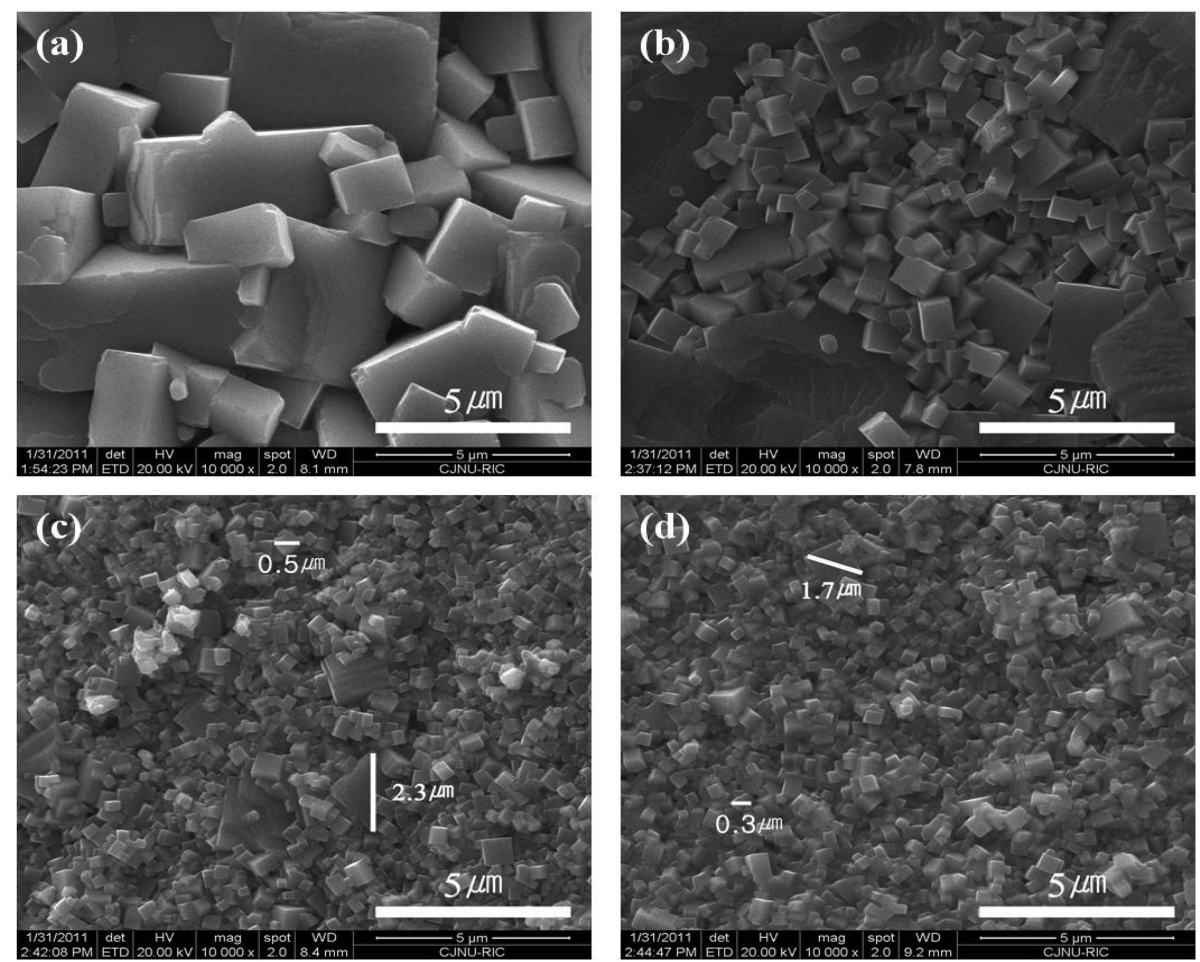

Fig. 4. SEM micrographs of nano milled KNLN-AS-xBCTZ ceramics sintered at $1050^{\circ} \mathrm{C}$ for $2 \mathrm{~h}:$ (a) $\mathrm{x}=0 \mathrm{~mol}$, (b) $\mathrm{x}=0.02 \mathrm{~mol}$, (c) $\mathrm{x}=$ $0.04 \mathrm{~mol}$ and $(\mathrm{d}) \mathrm{x}=0.05 \mathrm{~mol}$.

로 감소하였으며, 그 이상 첨가될 경우 일정하게 유지되 는 현상을 나타내고 있는 반면에 $\mathrm{x}$ 가 증가 함에 따라 $\mathrm{T}_{\mathrm{O}-\mathrm{T}}$ 는 $65^{\circ} \mathrm{C}$ 에서 $-4^{\circ} \mathrm{C}$ 로 급격히 감소하고 있다. Fig. $3(\mathrm{~b})$ 의 결과에 따르면 $\mathrm{x}=0.00 \mathrm{~mol}$ 인 경우 $\mathrm{T}_{\mathrm{O}-\mathrm{T}}$ 상전이 온도 는 실온보다 높으므로, 상온에서의 결정구조는 사방정계 이며, $\mathrm{x}=0.02 \mathrm{~mol}$ 인 경우에는 $\mathrm{T}_{\mathrm{O}-\mathrm{T}}$ 상전이 온도는 실온 을 나타내고 있다. 이는 실온에서 사방정계와 정방정계가 공존하고 있는 것을 나타내며, 또한, $\mathrm{x}=0.04 \mathrm{~mol}$ 이상에서 $\mathrm{T}_{\mathrm{O}-\mathrm{T}}$ 상전이 온도는 실온보다 낮은 온도를 나타내므로, 실 온에서 존재하는 결정상은 정방정계상임을 알 수 있다. 이러한 결과는 X선 회절 결과(Fig. 2)와 잘 일치하고 있
는 것을 알 수 있다.

$\mathrm{BCTZ}$ 첨가량에 따른 소결된 시편의 미세구조의 변화를 주사전자현미경(SEM)을 이용하여 관찰한 결과를 Fig. 4 에 나타내었으며, 각 조성에서의 소결 밀도의 변화를 Fig. 5에 나타내었다. BCTZ가 첨가되지 않은 시료의 경우 4 5 $\mu \mathrm{m}$ 의 큰 입경이 사이에 $2 \mu \mathrm{m}$ 근처의 입경을 갖는 입자 일부 존재하고 있는 것을 알 수 있다. $\mathrm{BCTZ}$ 의 치환량 이 $0.02 \mathrm{~mol}$ 로 증가함에 따라 $1 \mu \mathrm{m}$ 정도의 작은 입경이 증가하고 또한 큰 입경의 입자는 더욱 성장하는 것을 알 수 있다. 한편, $\mathrm{BCTZ}$ 의 첨가량이 $0.04 \mathrm{~mol}$ 로 증가할 경 우 $300 \mathrm{~nm}$ 의 작은 입경을 갖는 입자가 사이에 $1 \sim 2 \mu \mathrm{m}$ 의 
다소 큰 입자가 일부 존재하고 있다. BCTZ의 첨가량이 $0.05 \mathrm{~mol}$ 까지 증가하면 큰 입경을 갖는 입자는 거의 소멸 되고 $300 \mathrm{~nm} 650 \mathrm{~nm}$ 의 $1 \mu \mathrm{m}$ 이하의 미세한 입경을 갖는 입자가 치밀하게 분포되어 있는 것을 알 수 있다. 즉, $\mathrm{BCTZ}$ 의 치환량이 증가할 수록 거대 입자는 소멸되고 $1 \mu \mathrm{m}$ 이하의 나노 크기의 미세한 입자가 치밀한 소결구 조를 형성한다. 이러한 현상은 전형적인 완화형 강유전 체 특징을 나타내는 $\mathrm{BCTZ}^{20)}$ 의 첨가량이 증가함에 따라 $\mathrm{KNN}$ 격자의 $\mathrm{A}, \mathrm{B}$ 자리의 불규칙성이 증가하고, 불규칙 한 모상내에 규칙화된 미소분역이 형성됨에 따라 규칙영 역과 불규칙영역 사이의 계면에서 전위구배가 형성되어 입성장을 위한 이온의 확산을 방해함으로써 입성장이 억 제되는 현상으로 해석될 수 있다.

또한 Fig. 5 에 나타낸 바와 같이 $\mathrm{BCTZ}$ 치환 량이 증 가하여 미세입경의 입자가 증가할수록 소결 밀도가 증가 하는 것을 알 수 있다.

$\mathrm{BCTZ}$ 첨가에 따른 압전특성을 분석하기 위하여 Fig. 6(a)에 첨가량에 따른 전기기계결합계수와 압전상수값의 변화를 나타내었다. $\mathrm{BCTZ}$ 가 첨가되지 않은 경우 압전상 수는 $145 \mathrm{pC} / \mathrm{N}$ 전기기계결합계수는 $34.7 \%$ 의 값을 나타 내었고, $\mathrm{BCTZ}$ 가 $0.02 \mathrm{~mol}$ 첨가 되었을 때 전기기계 결 합계수 약 $41 \%$, 압전상수 $185 \mathrm{pC} / \mathrm{N}$ 으로 모두 최대 값 을 나타낸 후 그 이상의 첨가 량에서는 압전상수 및 전 기기계결합계수는 감소하는 경향을 나타내고 있다. 이러 한 현상은 Figs. 1, 2에서 설명한 바와 같이 $\mathrm{BCTZ}$ 가 첨 가되지 않은 상온에서 사방정상 만이 존재하여 자발분극 방향은 [101]만이 존재하며, $\mathrm{x}=0.02 \mathrm{~mol}$ 첨가된 경우 사 방정계와 정방정계가 공존함으로써 자발분극방향이 [101], [100]로 증가하게 되는 현상으로 해석된다. ${ }^{21)}$ 한편, BCTZ 의 치환량이 $0.04 \mathrm{~mol}$ 이상으로 증가됨에 따라 소결 밀도 는 증가하지만 상온에서 정방정상 만이 존재하여, 자발분 극 방향은 [100]방향 만이 존재하므로 자발분극수가 감소

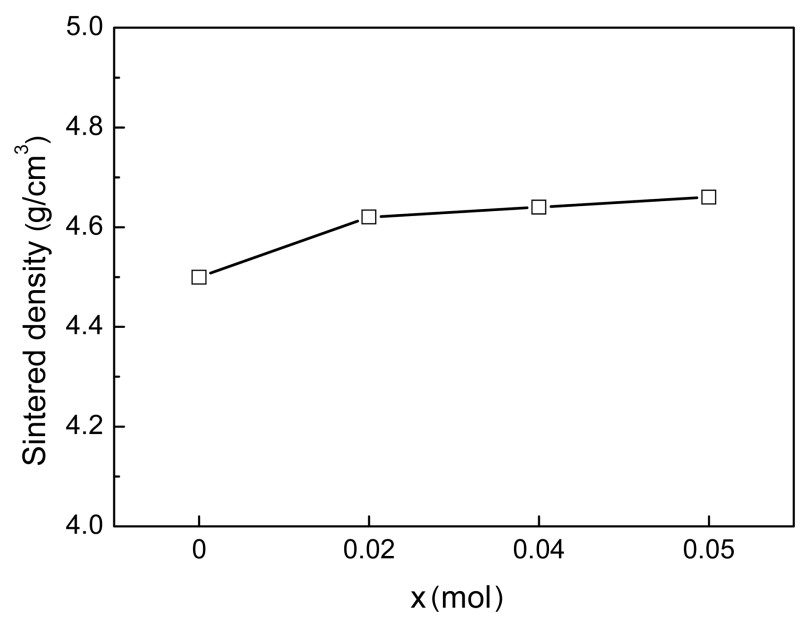

Fig. 5. The variations of density as a function of composition.
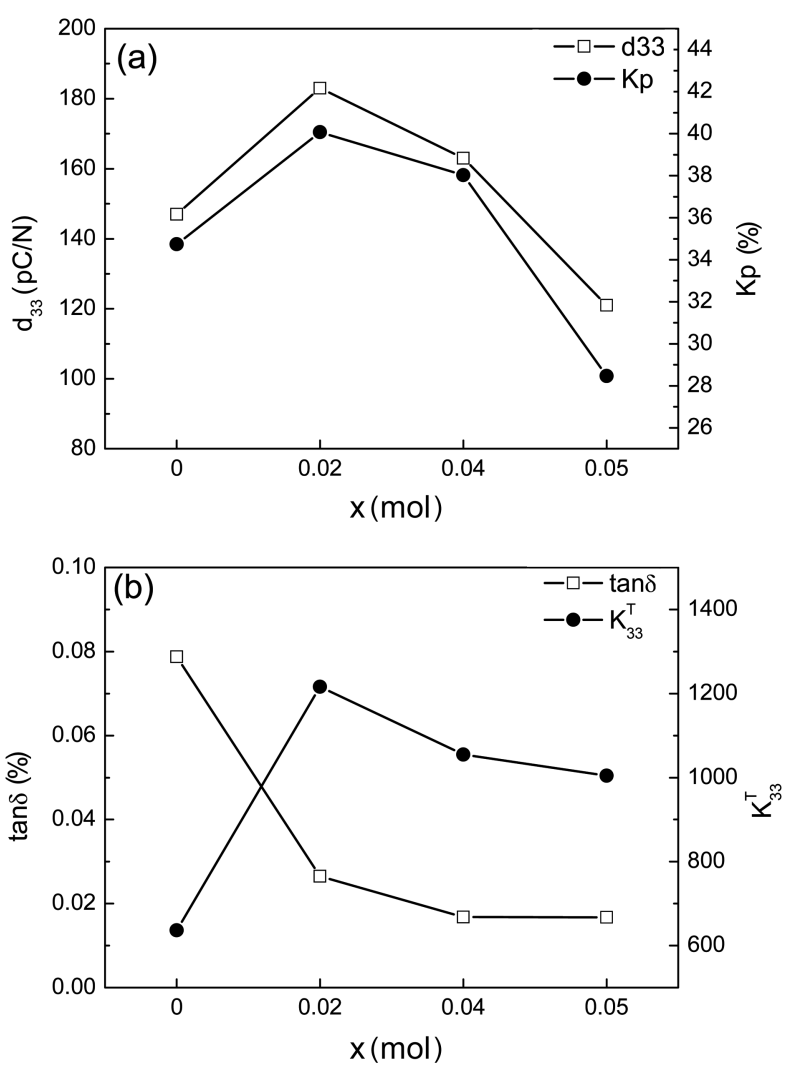

Fig. 6. Variation of piezoelectric and dielectric properties as a function of BCTZ content in KNLN-AS-xBCZT ceramics: (a) $k_{p}$ and $\mathrm{d}_{33}$, (b) $\tan \delta$ and $\mathrm{K}_{33}{ }^{\mathrm{T}}$ (measured at $1 \mathrm{kHz}$ ).

하여 압전상수 및 전기기계결합계수가 감소하게 된다. 또 한 $1 \mu \mathrm{m}$ 이하의 입경을 갖는 입자가 증가하여, 내부응력 이 큰 $90^{\circ}$ 분역이 증가하고, 이는 분역반전을 어렵게 하 므로 분역 이동도를 감소시키는 현상으로 해석된다. ${ }^{22)} \mathrm{x}=$ $0.05 \mathrm{~mol}$ 첨가된 경우 미세구조에서 알 수 있듯이 대부 분의 입경은 $\mathrm{nm}$ 크기로 존재하여, $90^{\circ}$ 분역의 내부응력을 더 욱 증가 시키고, 분역 반전 현상을 감소시킴에 따라 압 전상수 및 전기기계결합계수는 더욱 감소하게 된다.

분극된 시료의 상온 $(1 \mathrm{kHz})$ 에서 유전상수 및 유전손실 의 변화를 Fig. 6(b)에 나타내었다. 유전상수는 사방정계 와 정방정계의 상공존 구역인 $\mathrm{x}=0.02 \mathrm{~mol}$ 에서 최대값을 나타낸 후 그 이상의 치환량에서 약간 감소하는 경향을 나타내고 있다. 상공존 조성에서 $\mathrm{x}=0.00 \mathrm{~mol}$ 조성에 비 하여 2 배 이상의 급격한 유전율의 증가 현상이 나타나는 것을 알 수 있다. 이러한 현상은 입경의 급격한 감소와 밀도의 증가 그리고 상 공존에 따른 자발 분극량의 증 가로 해석될 수 있다. 이것은 능면정계와 정방정계가 공 존하는 경우 최적의 압전유전 특성을 나타내는 납계의 압 전세라믹스와 유사한 현상으로 해석된다. ${ }^{23)}$ 또한, 유전손 실은 유전율 변화와 반대로 첨가량이 증가할수록 감소하 는 경향을 나타내고 있다. 특히 $\mathrm{BCTZ}$ 가 첨가되지 않은 
시편에 비하여 $\mathrm{x}=0.02 \mathrm{~mol}$ 첨가된 경우 급격한 감소를 보 여 준다. 이러한 현상은 미세구조와 밀도변화의 결과에서 알 수 있듯이 $\mathrm{BCTZ}$ 가 첨가됨에 따라 입계의 정합성이 향상되어 입계에 의한 유전손실이 감소하며 밀도증가에 따 라 발생하는 현상으로 해석될 수 있다.

압전특성의 변화를 상세히 관찰하기 위하여 $\mathrm{BCTZ}$ 첨가 량에 따라 상온에서 측정한 P-E 이력곡선 Fig. 7(a) 와 잔류분극 및 항전계의 변화를 Fig. 7(b)에 정리하였다. $\mathrm{BCTZ}$ 가 첨가되지 않은 경우 상온에서 사방정계 결정구 조를 갖으며, [101]의 자발 분극 방향 이 존재한다. 이 는 항전계를 증가 시키는 $90^{\circ}$ 분역이 존재하지 않음을 의 미하고, 또한 큰 입경을 갖는 미세구조로 인하여 분역이 동도가 증가하여 $5 \mathrm{kV} / \mathrm{cm}$ 의 낮은 항전계값을 나타내며 잔 류분극값 역시 $19 \mu \mathrm{C} / \mathrm{cm}^{2}$ 의 최대값을 나타낸다.

한편, $\mathrm{BCTZ}$ 치환량이 증가함에 따라 잔류분극의 감 소와 항전계증가와 함께 이력곡선은 기울어지며, 넓어지 는 형상으로 변화하게 된다. 이러한 조성에 따른 이력곡 선의 변화가 $\mathrm{CaTiO}_{3}$ 가 첨가된 $\mathrm{KNN}-\mathrm{LS}$ 세라믹스계에서 관찰되었다. ${ }^{24)} \mathrm{BCTZ}$ 의 첨가량에 따른 항전계의 증가와 잔 류분극의 감소는 입경감소와 상온에서 정방정상의 출현
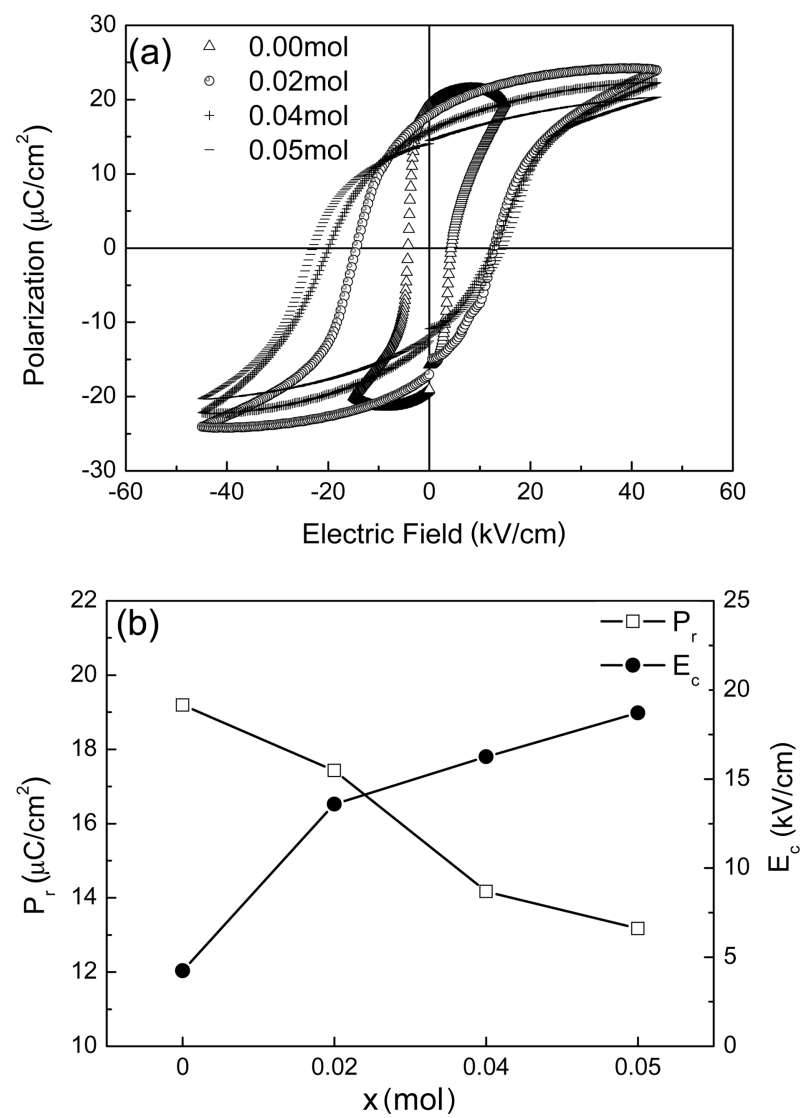

Fig. 7. (a): P-E loops of the KNLN-AS-xBCTZ ceramics with $x=0$, $0.02,0.04,0.05$ mol and (b) Variations of $P_{r}$ and $E_{c}$ with $x$ for the KNLN-AS-BCZT-x ceramics.
에 의한 $90^{\circ}$ 분역의 내부응력증가에 의한 현상으로 해석 되며, 사방정상이 소멸되고, 정방정상만이 존재하며, 입경 이 나노크기로 감소하기 시작하는 $\mathrm{x}=0.04 \mathrm{~mol}$ 이상에서 항전계의 증가와 잔류분극의 감소가 발생하고 있다.

\section{4. 결 론}

본 연구에서는 고에너지밀을 사용하여 혼합/분쇄한 KNLN-AS-xBCTZ계 세라믹스의 BCTZ첨가가 KNN계 압 전세라믹스에 미치는 효과를 연구하였다. KNN계 세라믹 스의 소결특성을 항상시키기 위하여, 나노 분쇄기를 이용 하여 분쇄한 결과 입자크기는 모든 시료에서 $180 ~ 200 \mathrm{~nm}$ 의 크기를 나타내고 있다.

$\mathrm{X}$ 선 회절 분석과 온도에 따른 유전율의 변화를 관찰 한 결과 $\mathrm{BCTZ}$ 가 $0.02 \mathrm{~mol}$ 치환되었을 때 상온에서 사방 정과 정방정이 공존하는 상공존 영역을 형성하였으며 조 성 중 가장 우수한 압전/유전 특성을 보였다. 이러한 현 상은 $\mathrm{BCTZ}$ 가 첨가되지 않은 상온에서 사방정상 만이 존 재하여 자발분극방향은 [101]만이 존재하며, $\mathrm{x}=0.02 \mathrm{~mol}$ 첨가된 경우 사방정계와 정방정계가 공존함으로써 자발 분극방향이 [101], [100]로 증가하게 되는 현상으로 해석 되며, $\mathrm{BCTZ}$ 의 치환량이 $0.04 \mathrm{~mol}$ 이상으로 증가됨에 따 라 소결 밀도는 증가하지만 상온에서 정방정상 만이 존 재하여, 자발분극 수가 감소하여 압전상수 및 전기기계 결합계수가 감소하게 된다.

또한 소결미세구조의 관찰결과로부터 알 수 있듯이 $1 \mu \mathrm{m}$ 이하의 입경을 갖는 입자가 증가하여, 내부응력이 큰 $90^{\circ}$ 분역이 증가하고, 이는 분역반전을 어렵게 하므로 분 역 이동도를 감소시키는 현상으로 해석되었으며 이러한 현상은 P-E 이력곡선을 이용하여 정량적으로 분석되었다.

\section{참 고 문 헌}

1. J. Long, H. Chen and Z. Meng, Mater. Sci. Eng. B, 99, 445 (2003).

2. M. J. Kim, J. C. Kim, Y. M. Kim, S. C. Ur and I. H Kim, Kor. J. Mater. Res., 15(7), 453 (2005) (in Korean).

3. Directive 2008/34/EC of the European Parliament and of the Council, Amending directive 2002/96/EC on Waste Electrical and Electronic Equipment (WEEE). Official Journal of the European Union, 2008 (March). Retrieved Nov. 1, 2011 from http://eur-lex.europa.eu/en/index.htm.

4. H. Nagata and T. Takenaka, J. Eur. Ceram. Soc., 21, 1299 (2001).

5. L. Egerton and D. M. Dillon, J. Am. Ceram. Soc., 42(9), 438 (1959).

6. V. J. Tennery and K. W. Hang, J. Appl. Phys., 39, 4749 (1968). 
7. R. Zuo, X. Fang and C. Ye, Appl. Phys. Lett., 90, 092904 (2007).

8. Y. Guo, K. Kakimoto and H. Ohsato, Appl. Phys. Lett., 85, 4121 (2004).

9. H. Y. Park, C. W. Ahn, H. C. Song, J. H. Lee, S. Nahm, K. Uchino, H. G. Lee and H. J. Lee, Appl. Phys. Lett., 89, 062906 (2006).

10. D. Lin, K. W. Kwok, K. H. Lam and H. L. W. Chan, J. Appl. Phys., 101, 074111 (2007).

11. R. Zuo, D. Lv, J. Fu, Y. Liu and L. Li, J. Alloys Comp., 476, 836 (2009).

12. Y. Saito, H. Takao, T. Tani, T. Nonoyama, K. Takatori, T. Homma, T. Nagaya and M. Nakamura, Nature, 432, 84 (2004).

13. H. Du, W. Zhou, F. Luo, D. Zhu, S. Qu, Y. Li and Z. Pei, J. Appl. Phys., 104, 034104 (2008).

14. M. Matsubara, T. Yamaguchi, W. Sakamoto, K. Kikuta, T. Yogo and S. Hirano, J. Am. Ceram. Soc., 88, 1190 (2005).
15. J. L. Jones, E. B. Slamovich and K. J. Bowman, J. Appl. Phys., 97, 034113 (2005).

16. M. S. Yoon, N. H. Khansur, W. J. Lee, Y. G. Lee and S. C. Ur, Adv. Mater. Res., 287, 801 (2011).

17. M. S. Yoon and S. C. Ur, Ceram. Int., 34, 1941 (2008).

18. H. Y. Park, K. H. Cho, D. S. Paik, S. Nahm, H. G. Lee and D. H. Kim, J. Appl. Phys., 102, 124101 (2007).

19. Y. Guo, K. Kakimoto and H. Ohsato, J. Phys. Chem. Solid., 65, 1831(2004).

20. S. W. Zhang, H. Zhang, B. P. Zhang and G. Zhao, J. Eur. Ceram. Soc., 29, 3235 (2009).

21. X. Sun, J. Deng, J. Chen, C. Sun and X. Xing, J. Am. Ceram. Soc., 92, 3033 (2009).

22. B. S. Kang, D. G. Choi and S. K. Choi., J. Kor. Phys. Soc., 32, S232 (1998).

23. B. Jaffe, R. S. Roth and S. Marzullo, J. Appl. Phys., 25, 809 (1954).

24. J. Wu, D. Xiao, Y. Wang, J. Zhu, W. Shi, W. Wu, B. Zhang and J. Li, J. Alloy. Comp., 476, 782 (2009). 